\title{
Prader-Willi syndrome in a child with mosaic trisomy 15 and mosaic triplo-X: a molecular analysis
}

Koenraad Devriendt, Gert Matthijs, Stephan Claes, Eric Legius, Willem Proesmans, Jean-Jacques Cassiman, Jean-Pierre Fryns

\begin{abstract}
A 3.3 year old girl with Prader-Willi syndrome (PWS) and mosaicism for two aneuploidies, $47, \mathrm{XXX}$ and $47, \mathrm{XX},+15$, is presented. The triplo-X cell line was found in white blood cells and fibroblasts, the trisomy 15 cell line in $50 \%$ of the fibroblasts. Using methylation studies of the PWS critical region and by polymorphic microsatellite analysis, the existence of uniparental maternal heterodisomy for chromosome 15 was shown in white blood cells. This provided a molecular explanation for the PWS in this child. In fibrolasts, an additional paternal allele was detected for markers on chromosome 15 , which is in agreement with the presence of mosaicism for trisomy 15 in these cells. This example provides direct evidence for trisomic rescue by reduction to disomy as a possible basis for PWS. Whereas the trisomy 15 was caused by a maternal meiosis I error, the triplo-X resulted from a postzygotic gain of a maternal $X$ chromosome, as shown by the finding of two identical maternal $X$ chromosomes in the $47, X X X$ cell line. Because the triplo- $X$ and the trisomy 15 were present in different cell lines, gain of an $X$ chromosome occurred either in the same cell division as the trisomy 15 rescue or shortly before or after.

$(\mp$ Med Genet 1997;34:318-322)
\end{abstract}

Centre for Human

Genetics, University Hospital Leuven,

Herestraat 49, B-3000

Leuven, Belgium

K Devriendt

G Matthijs

$S$ Claes

E Legius

J-J Cassiman

J-P Fryns

Paediatric Nephrology Unit, University

Hospital Leuven,

Belgium

W Proesmans

Correspondence to: Dr Devriendt.

Received 31 May 1996 Revised version accepted for publication 18 November 1996 been described for UPD involving other chromosomes, for example, in UPD2 mat, UPD9 mat, UPD11 pat, and UPD16 mat..$^{8-11}$ The finding of maternal heterodisomy for chromosome 15 in the majority of UPD 15 mat cases, ${ }^{12}$ as well as a correlation with advanced maternal age, ${ }^{13}$ provide additional indirect evidence to support trisomy rescue as a mechanism leading to UPD in PWS.

We present a patient with features of PWS who has mosaicism for trisomy 15 and for triplo-X, present in different cell lines. This is the first patient with trisomy 15 surviving beyond infancy on whom clinical follow up is provided. Molecular studies were undertaken to trace the events that led to this complex chromosomal aberration.

\section{Case report}

This girl is the first child of healthy, unrelated parents. The mother has five older, healthy children from two previous marriages. At the time of delivery, the mother was 42 years and the father 40 years old. During pregnancy, fetal movements were reduced, but there was no polyhydramnios. Birth weight at a gestational age of 38 weeks was $2140 \mathrm{~g}$ (10th centile $=2400$ g), length $41 \mathrm{~cm}$ (10th centile=45 $\mathrm{cm}$ ), head circumference $31.5 \mathrm{~cm}$ (10th centile). The neonatal clinical findings have been reported previously. ${ }^{15}$ During infancy, severe hypotonia persisted. Nasogastric tube feeding was necessary until the age of 5 months, while poor feeding persisted until about 3 years of age. A perimembranous ventricular septal defect (VSD) was present, which had closed spontaneously by the age of 6 months. She has a bicuspid aortic valve and mild peripheral pulmonary stenosis. At the age of 6 months, acute pyelonephritis led to the detection of bilateral vesicoureteral reflux with horseshoe kidneys. Ureter reimplantation was performed on both sides. There was constipation, with rectal prolapse during the first two years of life. Her psychomotor development is severely delayed. She could sit at the age of 2.5 years and started to walk at the age of 3.3 years (fig $1 \mathrm{~A}, \mathrm{~B}$ ). She is still hypotonic, but less pronounced than during infancy. There is almost no speech development. The feeding problems have disappeared, and she has gradually developed an increased appetite. She now even asks for more food. The parents describe her as stubborn and easily frustrated. Her weight is $8.3 \mathrm{~kg}$ ( $3 \mathrm{rd}$ centile $=12.3 \mathrm{~kg})$, length $81 \mathrm{~cm}$ ( $3 \mathrm{rd}$ centile $=91 \mathrm{~cm}$ ), and head circumference $44 \mathrm{~cm}$ ( $3 \mathrm{rd}$ centile $=47.1 \mathrm{~cm}$ ). There is no truncal obesity. The hands and feet are short; hand length is $7.4 \mathrm{~cm}$ (50th centile for 3 months), finger length is $3.3 \mathrm{~cm}$ (50th centile for 9 

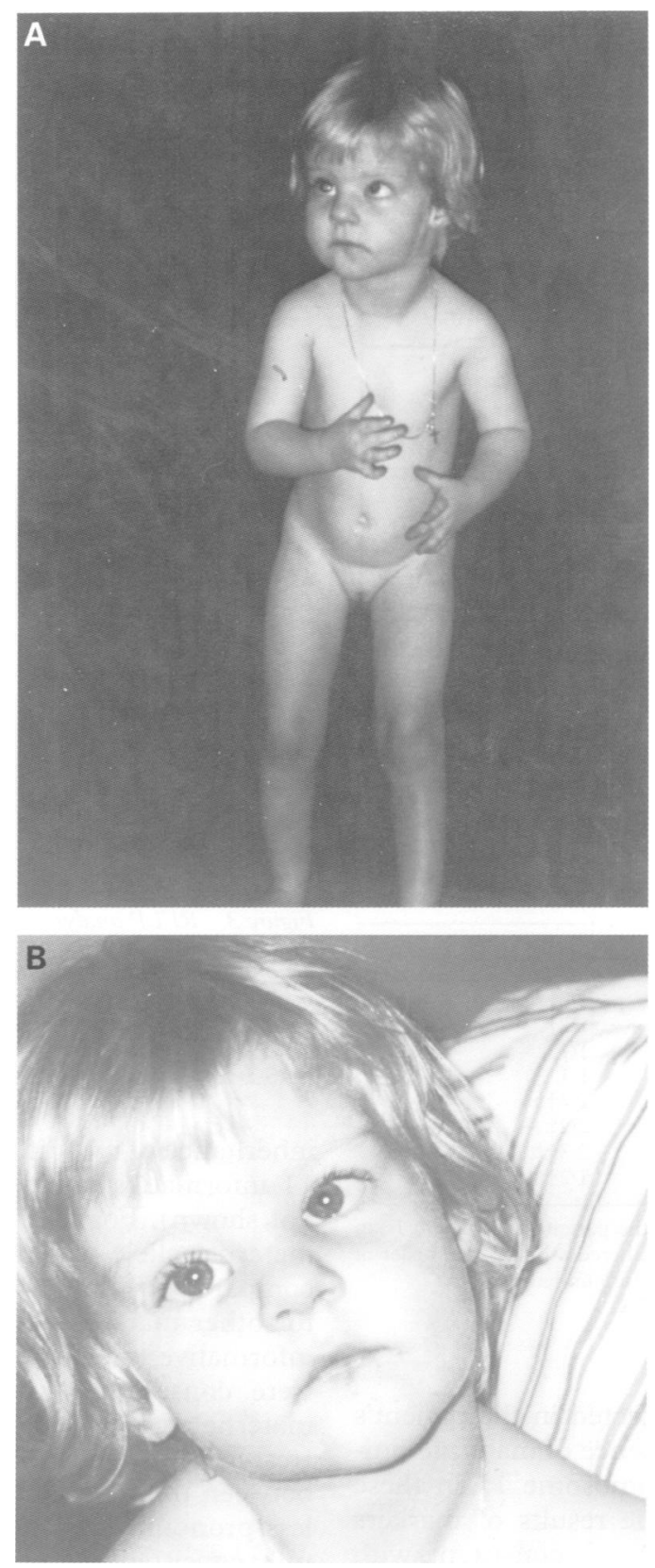

Figure 1 Clinical features of the patient at the age of 3.3 years. (A) Note the small hands, with clinodactyly of the fifth fingers, strabismus, poor facial expression, and downturned mouth. There is no truncal obesity. (B) Detail of the facial features.

months), and foot length is $10 \mathrm{~cm}$. There is clinodactyly of the fifth fingers. There are bilateral epicanthic folds and internal strabismus of the left eye. The saliva is sticky. The external genitalia are small and the anus is anteriorly placed.

\section{Methods}

Routine Giemsa and T banded chromosomes were obtained from peripheral blood lymphocytes and cultured skin fibroblasts.

DNA was extracted by standard methods from peripheral white blood cells (WBC) from the patient and her parents, and from cultured skin fibroblasts from the patient. Analysis of the methylation pattern in the Prader-Willi critical region on chromosome $15 \mathrm{q} 11$ was done by Southern blot analysis, using the probe PW71 after digestion with HindIII and $\mathrm{HpaII}^{16}$ and probe DN34 after digestion with EcoRI and HpaII. ${ }^{17}$ The following probes were used to analyse restriction fragment length polymorphisms (RFLPs) on the X chromosome: p1.8 (BgII digestion), p114.12 and XJ1.2 (BclI digestion), XJ2.3 and pERT 87.15 (TaqI digestion). Data collection and densitometric analysis was done using a PhosphoImager (Molecular Dynamics).

Analysis of microsatellite markers mapping to chromosome 15 and the $\mathrm{X}$ chromosome was performed by means of the polymerase chain reaction (PCR). The relative order of the markers for chromosome 15 was: 15 pterD15S210, D15S122, D15S165, APW, D15S123, FES, D15S107, D15S120-15qter. For the $\mathrm{X}$ chromosome, the relative order of analysed markers was: Xpter-DXS996, DXS999, DXS989, DMD49, DXS1068, DXS1003, DXS991, AR, DXS98, DXS990, DXS178, DXS1001, DXS425, HPRT, DXS984, DXS1227, DXS1193, factor 8-Xqter. Oligonucleotide primer sequences and map information were obtained from GDB and from Gyapay et al. ${ }^{18}$ One of each primer pair was fluorescently labelled (FITC, fluorescein-isothiocyanate). Genomic DNA (300 ng) was used for 30 cycles in an amplification in $50 \mu \mathrm{l}$ of PCR mix containing 200 $\mu \mathrm{mol} / 1 \mathrm{dNTPs}, 0.5 \mu \mathrm{mol} / 1$ each primer, and $1 \mathrm{U}$ Taq polymerase (Perkin-Elmer). Cycling conditions were: one minute at $94^{\circ} \mathrm{C}$, one minute at $55^{\circ} \mathrm{C}$, and one minute at $72^{\circ} \mathrm{C}$. All PCR products were electrophoresed on an ALF DNA sequencer (Pharmacia Biotech) and analysed using Fragment Manager software (Pharmacia Biotech). Using the described PCR conditions, the signal intensities could be interpreted in terms of number and dose of alleles.

$\mathrm{X}$ inactivation was measured by Southern blot analysis of a methylation sensitive RFLP at the PGK locus. ${ }^{19}$ Twelve $\mu \mathrm{g}$ of genomic DNA was digested with PstI and BstXI, after which the mixture was divided into two: one sample was digested further with $\mathrm{HpaII}$ and the other was not. Both samples were loaded onto $0.8 \%$ agarose in adjacent lanes, blotted, and the filter was hybridised with the $\mathrm{pSPT} / \mathrm{PGK}$ probe, as described. The ratio of the 1.05 and $0.9 \mathrm{~kb}$ fragment was determined by densitometry.

\section{Results}

Karyotype analysis on peripheral WBC from two different blood samples showed a 47, XXX karyotype in all 35 cells examined. Primary skin fibroblast cultures showed $47, \mathrm{XXX}$ in 15 and $47, X X,+15$ in 16 cells. No cells with other karyotypic anomalies were detected.

An exclusively maternal methylation pattern in the PWS locus on chromosome $15 \mathrm{q} 11$ was observed in the WBC using probes PW71 and DN34 (results not shown). In skin fibroblasts a combination of a maternal and paternal pattern was detected. To distinguish between a deletion in 15q11 and UPD15 mat, eight polymorphic microsatellite markers distributed along chromosome 15 were analysed in both the parents (WBC) and the patient (WBC and fibroblasts). For three fully informative markers, D15S123, FES, and D15S107, only 

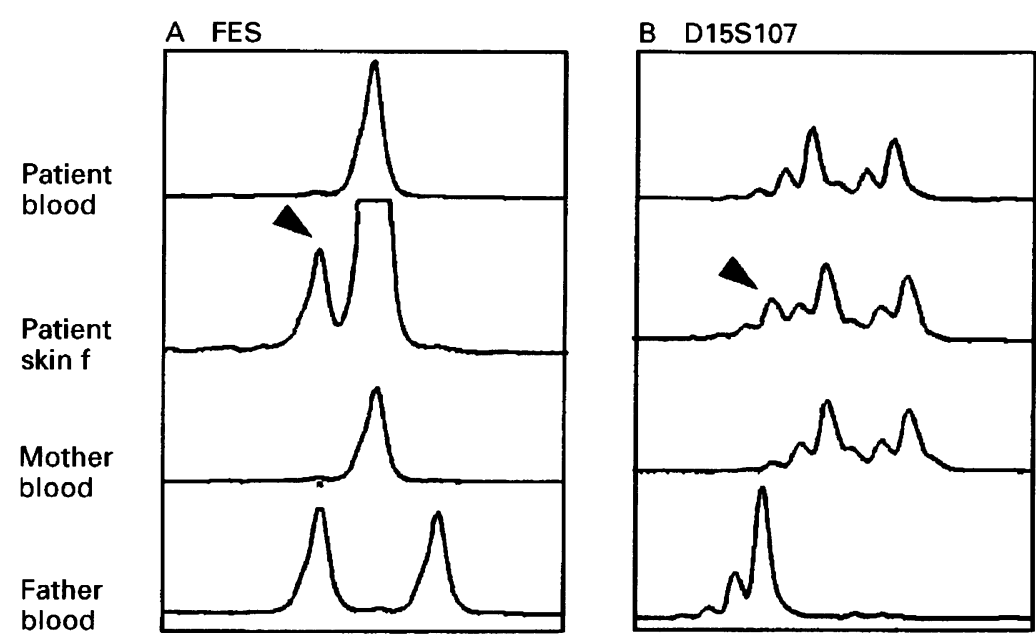

Figure 2 Analysis of polymorphic microsatellite markers on chromosome 15. The polymorphic microsatellite markers FES and D15S107 were analysed in the patient (white blood cells and skin fibroblasts) and in the white blood cells of the mother and father. In white blood cells of the patient, two different maternal alleles were present for marker D15S107, indicating the presence of uniparental heterodisomy for chromosome 15. The mother and patient were homozygous for the FES allele. In skin fibroblasts, an additional paternal allele is found at a lower dose compared to the maternal alleles (arrow), which is in accordance with the finding of trisomy 15 in approximately half of the cells.

Table 1 Microsatellite analysis showing maternal heterodisomy for chromosome 15

\begin{tabular}{lllll}
\hline & Father & Mother & Patient $(S F)$ & Patient $(W B C)$ \\
\hline D15S210 & $1 / 3$ & $1 / 2$ & $1 / 2 / 3^{\star}$ & $1 / 2 \dagger \ddagger$ \\
D15S122 & $1 / 2$ & $1 / 2$ & $1 / 2$ & $1 / 2 \dagger$ \\
D15S165 & $1 / 2$ & $1 / 1$ & $1 / 2^{\star}$ & $1 / 1$ \\
APW & $1 / 2$ & $1 / 1$ & $1 / 1$ & $1 / 1$ \\
D15S123 & $1 / 4$ & $2 / 3$ & $\underline{1} / 2 / 3^{\star}$ & $2 / 3 \dagger \ddagger$ \\
FES & $1 / 3$ & $2 / 2$ & $\underline{1} / 2^{\star}$ & $2 / 2 \ddagger$ \\
D15S107 & $1 / 1$ & $2 / 3$ & $\underline{1} / 2 / 3^{\star}$ & $2 / 3 \dagger \ddagger$ \\
D15S120 & $2 / 3$ & $1 / 2$ & $1 / 2 / \underline{3}^{\star}$ & $1 / 2 \dagger \ddagger$ \\
\hline
\end{tabular}

Haplotypes of polymorphic microsatellites on chromosome 15 in the parents and patient (skin fibroblasts (SF) and white blood cells (WBC)). The alleles are numbered arbitrarily in order of length. The paternal alleles detected in skin fibroblasts of the patient are underlined.

$\star$ With a lower dose of the paternal allele compared to maternal alleles.

† Indicative of maternal heterodisomy for chromosome 15.

¥ Compatible with maternal disomy for chromosome 15 .

maternal alleles were detected in the patient's WBC, indicating the presence of maternal uniparental disomy for chromosome 15 in these cells (fig 2 , table 1 ). The results of markers D15S210 and D15S120 are consistent with this. In the patient's fibroblasts, an allele of paternal origin was detected for six markers (D15S210, D15S165, D15S123, FES, D15S107, and D15S120) (table 1, fig 2). The dosage of the paternal allele was lower compared to the maternal alleles, which is consistent with the observed mosaicism for trisomy 15. Two different maternal alleles were detected for five informative markers distributed along chromosome 15: D15S210, D15S122, D15S123, D15S107, and D15S120. For the other three markers, the mother was homozygous and therefore not informative. All data were fully compatible with the presence of maternal heterodisomy for chromosome 15 and, in the trisomic fibroblasts, the presence of a paternal chromosome 15 .

To determine the parental origin of the additional X chromosome, 18 polymorphic microsatellite markers and five RFLPs on the $X$ chromosome were analysed, both in the parents (WBC) and the patient (WBC and fibroblasts). Maternal heterodisomy for the $\mathrm{X}$ chromosome was excluded by the absence of

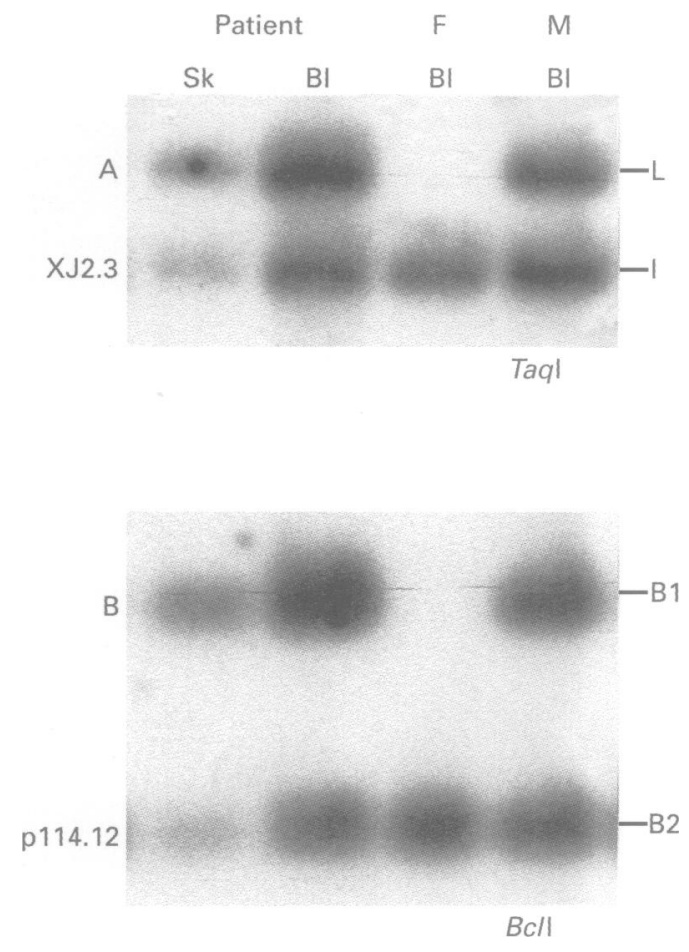

Figure 3 RFLP analysis for markers on the $X$

chromosome. Southern blot analysis of two polymorphic loci using probes $X \mathfrak{F} 2.3(A)$ and $p 114.12$ (B) on the patient's skin fibroblasts $(S k)$ and white blood cells $(B l)$ and white blood cells of the father $(F)$ and mother $(M)$. In the patient, the dose of the maternal allele ( $L$ in panel $A ; B 1$ in panel $B$ ) was approximately double the dose of the paternal allele.

inheritance of two different maternal alleles for 11 informative microsatellite markers (results not shown). For four informative RFLPs, the maternal allele was present in a double dose compared to the paternal allele (fig 3, results for other markers not shown). Also, for eight informative microsatellite markers, the results were consistent with a double dose of the maternal compared to the paternal allele (results not shown). The dose difference between the maternal and paternal alleles was less pronounced in fibroblasts, which is again fully consistent with the presence of a triplo-X karyotype in only half of the fibroblasts. This is evidence for a postzygotic event, with gain of a maternal X chromosome.

$\mathrm{X}$ chromosome counting is an early step in the process of $\mathrm{X}$ inactivation. ${ }^{20}$ The $\mathrm{X}$ inactivation pattern in this patient was studied as a means to determine the timing of this postzygotic event leading to $\mathrm{X}$ chromosome duplication. After digestion with a methylation sensitive restriction enzyme, the unmethylated allele(s) representing the active $\mathrm{X}$ chromosome(s) disappear. The father was hemizygous for the $0.9 \mathrm{~kb}$ allele detected with the PGK probe, whereas the mother was homozygous for the $1.05 \mathrm{~kb}$ allele (fig 4). In the patient $\mathrm{X}$ inactivation in peripheral WBC carrying the triplo-X, both the maternal and paternal $\mathrm{X}$ chromosomes underwent inactivation in a fraction of cells (fig 4, lane 5). Dosage analysis by densitometry showed that after digestion with a methylation sensitive restriction enzyme (fig 4, lane 6), the signal is reduced to two thirds for both alleles, suggesting that one active $\mathrm{X}$ chromosome is present in these cells 


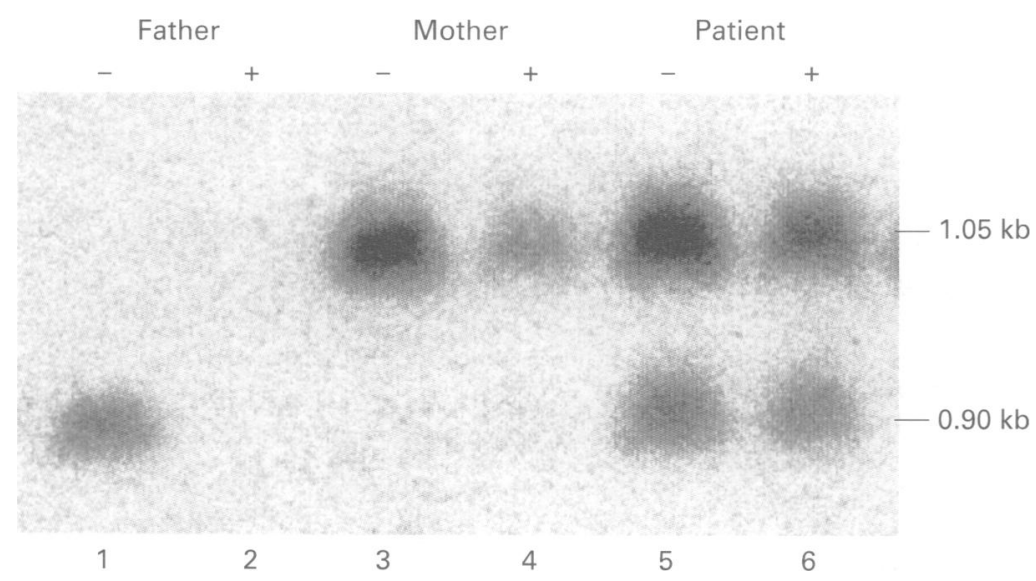

Figure $4 X$ inactivation analysis by Southern blot of the PGK gene. DNA from WBC from the father $(F)$, mother $(M)$, and patient $(P)$ was digested with PstI and BstXI. DNA in lanes 2,4 , and 6 was further digested with the methylation sensitive restriction enzyme $H$ paII. The father is hemizygous for the $0.9 \mathrm{~kb}$ allele, the mother homozygous for the 1.05 $k b$ allele. After Hpall digestion, the $0.9 \mathrm{~kb}$ allele completely disappeared in the father as expected for an unmethylated, active $X$ chromosome. In the patient, $X$ chromosome inactivation is not abnormal, with either the maternal or paternal $X$ chromosomes undergoing $X$ inactivation in a fraction of cells. Dosage analysis by densitometry showed that the dose of inactivated (methylated) X chromosomes (lane 6) versus the dose of all three $X$ chromosomes (lane 5) was 2/3. Therefore, only a single active $X$ chromosome is present in each cell, with the remaining two being inactivated.

and the remaining two are inactivated. $\mathrm{X}$ inactivation is therefore random.

\section{Discussion}

The clinicial features in the present patient fit the diagnosis of PWS according to the criteria of Holm et al. ${ }^{21}$ UPD15 mat was shown in WBC, both by means of methylation analysis at the PWS critical region and by microsatellite analysis, consistent with this diagnosis. However, her phenotype was atypical, as the severity of, for instance, the mental and growth retardation and feeding difficulties was much more pronounced. Also, additional findings not commonly observed in PWS were present, including a heart defect, facial dysmorphism, and vesicoureteral reflux. These features can be attributed to the presence of a mosaic trisomy 15 , found in $50 \%$ of the skin fibroblasts. Only a few liveborn patients with mosaic trisomy 15 have been reported and most die early in infancy, but nevertheless a specific phenotype is emerging, as reviewed by Milunsky et $a l^{22}$ The most consistent findings are severe hypotonia with feeding difficulties, typical craniofacial dysmorphism, mild skeletal anomalies, and congenital heart disease. ${ }^{22}$ The severe hypotonia could possibly be attributed to the concomitant UPD15 mat, but more cases need to be studied to delineate the phenotype of trisomy 15 mosaicism. Truncal obesity is not yet present in our patient at the age of 3.3 years, unlike many other PWS patients at this age. This could be explained by the mosaicism for UPD15 mat, which is expected to result in a milder phenotype. Alternatively, the mosaic trisomy 15 could cause failure to thrive.

The finding in this patient of UPD15 mat in WBC, together with the mosaicism for trisomy 15 in fibroblasts (with a paternal chromosome 15 in $50 \%$ of the cells), is compatible with trisomy rescue. ${ }^{12}{ }^{23}$ For all informative markers on chromosome 15, maternal heterodisomy was observed, which is compatible with a nondisjunction event during maternal meiosis $\mathrm{I}$. Theoretically, a meiosis II error can also result in heterozygosity for chromosomal fragments, as a result of crossovers. In meiosis II errors, however, as a rule, homozygosity for the pericentromeric regions is observed, since these regions are excluded from crossovers. The most centromeric marker on chromosome $15 \mathrm{q}$ that was informative in the present patient was D15S210 and showed heterozygosity. ${ }^{18} \mathrm{~A}$ meiosis I error is thus most plausible, though one cannot exclude with certainty a meiosis II error with a crossover between marker D15S210 and the centromere. Moreover, a maternal age of 42 years for the present patient is consistent with previous reports in which an increased average maternal age was observed in mothers of patients with UPD 15 mat. ${ }^{13} 14$

There are other mechanisms causing UPD, in each instance also requiring two errors. ${ }^{12} 1323$ In the present patient, a postzygotic gain of a maternal chromosome 15 is ruled out by the presence of maternal heterodisomy. Gamete complementation cannot explain the finding of a trisomy 15 cell line in the present case.

Interestingly, mosaicism for triplo-X was also observed in the present case and two other reported patients with PWS also carried a cell line with aneuploidy for a sex chromosome. The patient reported by Stallard and Sommer ${ }^{24}$ showed 45,X/47,XY,+15 mosaicism. Butler et at described a female with Prader-Willi syndrome with $47, \mathrm{XXX} / 46, \mathrm{XX}$ mosaicism and UPD15 mat. In this latter patient, the maternal heterodisomy for chromosome 15 implicates a maternal meiotic error, but the origin of the triplo-X was not investigated. Analysis of polymorphic markers on the $\mathrm{X}$ chromosome in the present patient showed the presence of two identical maternal $\mathrm{X}$ chromosomes in the triplo-X cell line. This is most likely the result of a postzygotic mitotic error, with mitotic non-disjunction or anaphase lag of two chromatids of a maternal X chromosome. ${ }^{25}$ Alternatively, a maternal meiosis II error might also lead to the presence of two identical maternal $\mathrm{X}$ chromosomes, but this would implicate the absence of detectable crossovers during meiosis I. This is unusual and therefore less probable. Also, in the event of a meiosis II error, an additional postzygotic correction with the loss of one $\mathrm{X}$ chromosome must have occurred to explain the observed mosaicism for $47, \mathrm{XXX} / 47, \mathrm{XX},+15$.

The presence of the triplo-X cell line in all lymphocytes analysed as well as in fibroblasts suggests a correction occurring early during embryonic development, before tissue differentiation. $\mathrm{X}$ chromosome inactivation analysis showed that only a single $\mathrm{X}$ chromosome is active in the WBC, the other two being inactivated. Also, the WBC had a different $\mathrm{X}$ inactivation pattern and involved either one of the two maternal and the paternal $\mathrm{X}$ chromosomes. Since the cells with the triplo-X must be clonal in origin, the normal $\mathrm{X}$ inactivation seen in the present patient can only be explained when $\mathrm{X}$ inactivation came after the error leading to the triplo- $\mathrm{X}$. Normal $\mathrm{X}$ inactivation 
occurs after counting of the $\mathrm{X}$ chromosomes early in embryonic development. ${ }^{20}$ Thus, we provide evidence that the error leading to the triplo-X in this patient occurred before counting of the $\mathrm{X}$ chromosomes. Also, abnormal $\mathrm{X}$ inactivation does not play a part in the severity of the phenotype of the present child.

In conclusion, the errors leading to the two aneuploidies have occurred in a different cell division, one meiotic and the other postzygotic, and are therefore unrelated. A third error, the loss of a paternal chromosome 15, has also occurred postzygotically. This raises the possibility that both postzygotic errors, trisomy 15 recue and gain of an $\mathrm{X}$ chromosome, are related and might have occurred at the same cell division. If not, in order to explain the observed mosaicism, they certainly must have occurred shortly after each other. It is not possible to distinguish between these possibilities, and more cases need to be studied to answer this question. The further study of all these patients will therefore be particularly interesting.

1 Ledbetter DH, Riccardi VM, Airhart SD, Strobel RJ, Keenan BS, Crawford JD. Deletions of chromosome 15 as a cause of the

2 Nicholls RD, Knoll JHM, Butler MG, Karam S, Lalande M. Genetic imprinting suggested by maternal heterodisomy in non-deletion Prader-Willi syndrome. Nature 1989;342: $281-5$

3 Cassidy SB, Lai LW, Erickson RP, et al. Trisomy 15 with loss of the paternal 15 as a cause of Prader-Willi syndrome due to maternal disomy. Am f Hum Genet 1992;51:701-8.

4 Purvis-Smith SG, Saville T, Manass S, et al. Uniparental disomy 15 resulting from 'correction' of an initial trisomy 15. Am $\mathcal{F}$ Hum Genet 1992;50:1348-50.

5 Morichon-Delvallez N, Mussat P, Dumez Y, Vekemans M. Trisomy 15 in chorionic villi and Prader-Willi syndrome at birth. Prenat Diagn 1993;13:307-8.

6 Birth. Prenat Diagn 1993;13:307-8. with both Prader-Willi and trisomy X syndromes. Am f with both Prader-Willi and trison

7 Christian SL, Smith AC, Macha M, et al. Prenatal diagnosis of uniparental disomy 15 following trisomy 15 mosaicism. Prenat Diagn 1996;16:323-32.

8 Willat LR, Davison BC, Goudie D, et al. A male with trisomy 9 mosaicism and maternal uniparental disomy for chromosome 9 in the euploid cell line. $\mathcal{F}$ Med Genet 1992 29:742-4
9 Vaughan J, Ali Z, Bower S, Bennett P, Chard T, Moore G. Human maternal uniparental disomy for chromosome 16 and fetal development. Prenat Diagn 1994;14:751-6.

10 Harrison K, Eisenger K, Anyane-Yeboa K, Brown S. Maternal uniparental disomy of chromosome 2 in a baby with trisomy 2 mosaicism in amniotic fluid culture. $\mathrm{Am} \mathcal{f} \mathrm{Med}$ Genet 1995;58:147-51.

11 Webb A, Beard J, Wright C, Robson S, Wolstenholme J, Goodship J. A case of uniparental disomy for chromosome 11. Prenat Diagn 1995;15:773-7.

12 Mutirangura A, Greenberg F, Butler MG, et al. Multiplex PCR of three dinucleotide repeats in the Prader-Willi/ Angelman critical region (15q11-13): molecular diagnosis and mechanism of uniparental disomy. Hum Mol Genet 1993;2:143-51.

13 Robinson WP, Lorda-Sanchez I, Malcolm S, et al. Increased parental ages and uniparental disomy 15: a paternal effect? Eur 7 Hum Genet 1993;1:280-6.

14 Gillesen-Kaesbach G, Robinson W, Lohmann D, KayaWesterloh S, Passarge E, Horsthemke B. Genotypephenotype correlation in a series of 167 deletion and nondeletion patients with Prader-Willi syndrome. Hum Genet 1995;96:638-43.

15 Fryns JP, Kleczkowska A, Lagae L, Kenis H, Van den Berghe H. A specific phenotype associated with trisomy 15 mosaicism. Ann Genet (Paris) 1993;36:129-31.

16 Dittrich B, Robinson WP, Knoblauch H, et al. Molecular diagnosis of the Prader-Willi and Angelman syndromes by detection of parent-of-origin specific DNA methylation in 15q11-13. Hum Genet 1992;90:313-15.

17 Driscoll DJ, Waters MF, Williams CA, et al. A DNA methylation imprint, determined by the sex of the parent, distinylation imprint, determined by the sex of the parent, distinguishes the Angelman
nomics 1992;13:917-24.

18 Gyapay G, Morisette J, Vignal A, et al. The 1993-1994 Généthon human genetic linkage map. Nat Genet 1994;7: 246-339.

19 Vogelstein B, Fearon ER, Hamilton SR, et al. Clonal analysis using recombinant DNA probes from the $\mathrm{X}$-chromosome. Cancer Res 1987;47:4806-13.

20 Migeon BR, Jeppesen P, Torchia BS, et al. Lack of $\mathrm{X}$-inactivation associated with maternal X-isodisomy: evidence for a counting mechanism prior to $\mathrm{X}$ inactivation during human embryogenesis. Am $\mathcal{F}$ Hum Genet 1996;58: 161-70.

21 Holm VA, Cassidy SB, Butler MG, et al. Prader-Willi syndrome: consensus diagnostic criteria. Pediatrics 1993; 91:398-402.

22 Milunsky JM, Wyandt HE, Huang XL, Kang XZ, Elias ER, Milunsky A. Trisomy 15 mosaicism and uniparental disomy (UPD) in a liveborn infant. Am F Med Genet 1996; 61:269-73.

23 Engel E. Uniparental disomy revisited: the first twelve years. Am f Med Genet 1993;46:670-4.

24 Stallard R, Sommer A. Trisomy 15 in a mosaic, double aneuploid two year old. Am F Hum Genet Suppl 1989;45: A92.

25 MacDonald M, Hassold T, Harvey J, Wang LH, Morton NE, Jacobs P. The origin of $47, \mathrm{XXY}$ and $47, \mathrm{XXX}$ aneuploidy: heterogeneous mechanism and role of aberrant recombination. Hum Mol Genet 1994;8:1365-71. 